\title{
Искусство
}

DOI: $10.24833 / 2541-8831-2019-3-11-179-188$

\section{КОММУНИКАТИВНЫЙ ПОТЕНЦИАЛ МУЗЫКАЛЬНОЙ ВЫРАЗИТЕЛЬНОСТИ}

\author{
М.В. Алексеева
}

Московский государственный технический университет гражданской авиации. Россия, 125993, Москва, Кронштадтский бульвар, 20.

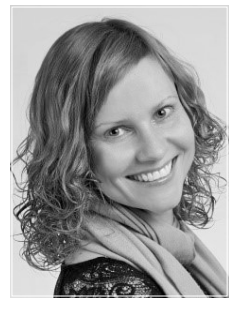

Как замечательно, что мы столкнулись с парадоксом. Теперь у нас есть надежда на продвижение!

Нильс Бор

В данной статье предлагается краткий обзор некоторых современных научных вызовов и парадоксов, а также связанных с этим социальных проблем. Обозначены ключевые проблемы в сфере изучения сознания в связи с работой учёных над созданием искусственного интеллекта. Вследствие подобных амбициозных устремлений современной науки особое значение приобретает доступ к индивидуальному миру личности, к конкретно-прочессуальному переживанию ею эмоциональных состояний, к её персональным креативным устремлениям.

Предложенные тезисные положения исследования коммуникативных и креативных возможностей музыкального языка, его качественных отличий от рассмотренного потенциала вербальной семантики дают ясное представление о том, что язык музыки имеет прямое отношение и к эмоциональной выразительности и к стимулированию процесса познания. В результате подобного резюме становится очевидным факт, что изучение вербальных и музыкальных выразительных возможностей, их сравнительный анализ в реалиях культурных и коммуникационных тенденций современности не ограничивается потребностями сферы искусства.

Далее предлагается некий взгляд на коммуникативные возможности музыкальной выразительности в связи со способностью музыки к передаче процесса протекания индивидуальных эмоций человека. Новизна данной статьи заключается в обосновании дальнейшего подробного изучения коммуникационных возможностей музыкальной выразительности, которые вне сферы искусства позволят открыть интерактивный доступ к эмочиональному миру индивида, его квалиа. В свою очередь, статус квалиа считается одной из самых острых и широко обсуждаемых проблем в современной философии, поскольку представители различных сфер науки нередко видят в нём ключ к пониманию природы сознания.

Ключевые слова: когнитивные науки, сознание, эмоции, интуиция, музыкальная семантика, творчество, мораль, искусственный интеллект 
$\mathrm{B}$

наше время в связи с множеством значимых научных открытий и социальных изменений мы стоим на пороге различных гносеологических преобразований, включая гуманитарные. За этим следует ряд значимых научных вопросов, за которые берутся современные учёные, ранее не входившие в круг их интересов по причине невозможности поиска обоснованных ответов.

Представители корпуса когнитивных наук, в числе которых биология, нейробиология, физиология, нейролингвистика, когнитивная психология и др. получили доступ к оборудованию, позволяющему фиксировать процессы внутри мозга, в том числе человека, и поставили сегодня амбициозную задачу - изучения сознания. Она, разумеется, имеет и прикладное значение, поскольку в ряде стран учёные работают над созданием искусственного интеллекта (ИИ), где процессы индивидуального сознания также обозначили своего рода «точку бифуркации» - творчество.

Спектр глобальных проблем, способных привести науку на порог серьёзных перемен, а также значимые в данном случае социальные преобразования можно представить следующим образом. Под искусственным интеллектом, в том числе понимается свойство интеллектуальных систем выполнять творческие функции, которые традиционно считаются прерогативой человека [Аверкин, ГаазеРапопорт, Поспелов, 1992]. Проблема написания художественных произведений, творчество перед компьютером уже стоит. Однако ряд крупных учёных, таких, как физик и математик Роджер Пенроуз, аргументируют невозможность получения процесса мышления на основе формальных систем [Penrose, 1989].

К примеру, нейрофизиолог Александр Каплан, принципиально отвергает способность машин к творчеству, понимаемому людьми как гениальное. В своих интервью он в качестве доказательства приводит пример с гипотезой Пуанкаре. Творчество ИИ построено на алгоритмах, a, по мнению учёного, творческий акт че- ловека может осуществляться задолго до вычленения каких-либо алгоритмов, иначе как Анри Пуанкаре смог выдвинуть гипотезу, которая была доказана Григорием Перельманом лишь спустя столетие, и почему это оказалось непосильной задачей для самого автора?

Абсолютное большинство учёных понимают незаменимую роль интуиции и эмоций в творческом процессе человека. В этой связи при изучении индивидуального сознания достаточно быстро очевидной для ярких умов планеты стала проблема ограниченности научного арсенала средств для дальнейшего продвижения к решению. В результате многие из них, так или иначе, стали предлагать различные пути к поиску ответов. Парадокс в данном случае оказался настолько значительным, что в наиболее радикальной версии серьёзные учёные поставили под сомнение саму научную картину мира.

Язык науки универсален, его отличают верификация, повторяемость, статистика, проверка данных и т.п. В этой связи во многом назначение научной деятельности имеет технологическую направленность с целью преобразования мира с практической стороны существования. Вселенная мысли, ассоциаций и жизненный опыт индивида уникальны и не могут быть включены в парадигму верификации вообще. Резюмируя подобное положение дел, Роджер Пенроуз заявил о том, что картина мира, не вмещающая в себя столь важную часть человеческого существования, как сознание, видимо, не верна. Позднее он предложил к рассмотрению гипотезу квантовой природы сознания [Penrose, 1989]. По сути, в рамках научной картины мира обмен индивидуально-уникальными проявлениями человеческой природы мышления исключается.

Представители различных научных направлений, занимающиеся проблемой сознания, всё чаще говорят о необходимости создания и вообще невероятной ценности новых теорий, способных предложить как адекватные решения проблем уже обозначенных, так и вме- 
щающие новейшие устремления авангарда познания.

Учёные различных сфер науки нередко сетуют, что даже по узкоспециализированным областям в мире выходит до трёхсот научных статей в неделю, а то и в день, их даже невозможно прочесть, что требует каких-то иных подходов и решений. Сейчас наука пришла к точке, когда индивидуальные данные интересны, но мы не знаем, как с ними справиться. В этом ключе актуальность приобретает и проблема связей с общественностью или PR в научной сфере, поскольку более чем очевидной становится необходимость донесения своей точки зрения до широкого круга как учёного сообщества, так и общественности в целом. Представляется необходимым поиск качественно новых способов обмена научной информацией, включая различные сферы учёного сообщества. В данном случае особую ценность приобретают инновационные теории философского уровня как непосредственно объясняющие феномен сознания, так и предлагающие качественно иные парадигмы работы с информацией в современном мире, включающие способы познания в принципе.

Философия сегодня также включена в процесс работы над ИИ, рассматривая два значимых вопроса: «Что такое ИИ, возможно ли его создание?» и «Каковы последствия, в особенности этические, создания ИИ для человечества?». Этические проблемы применительно к ИИ также подразумевают глубокий уровень осмысления дальнейшего развития представлений о морали в социуме и примирения общественной и индивидуальной позиций, что приводит нас опять к проблеме сознания. Этические представления множества конкретных людей имеют достаточно широкий спектр, а машины, будучи нечеловекомерными, обладая несравнимыми физическими и вычислительными преимуществами, должны будут иметь некую программу действий по определённым стандартам. Эта проблема тянет за собой значимость вопросов целеполагания как в социальной среде людей, так и при создании искусственного интеллекта.

К одной из сложнейших социальноонтологических проблем современного мира можно отнести выход из парадигмы бинарного мышления, что имеет прямую корреляцию с социальными поисками этических ориентиров. Культурные эпохи XX века Модерн и Постмодерн с о своим плюрализмом идей, мнений, традиций и знаний привели к тому, что в наше время уходит как культурный вызов необходимость осмысления поступков в контексте добра и зла. Категорический императив ${ }^{1}$ И. Канта и резюмирующая сентенция о свободе махать руками, которая заканчивается у носа соседа, прочертили линию демаркации, замыкая многовековые размышления человечества о положительной или негативной оценке конкретных феноменов.

Социальная толерантность и диалог культур, порождённые глобализацией, наряду с растущим и изменяющим характер бытования информационным объёмом, обозначили новый вызов эпохи. Он лежит в русле ассимиляции мультикультурализма в его конкретных проявлениях возможностями одного сознания, которое не лишено при этом ментальности определённого социума. Здесь уместно отметить как пожизненную специализацию нейронов мозга при обучении ${ }^{2}$, так и различия в образе мышления конкретных культур как минимум по двум типам: холистический (где доминируют причинно-следственные связи или классификация объектов по отношениям) и аналитический (в его рамках предпочтительна классификация феноменов и явлений мира или таксономическая категоризация объектов) [Александров, 2018].

\footnotetext{
1 «Поступай так, чтобы ты всегда относился к человечеству и в своём лице, и в лице всякого другого так же как к цели, и никогда не относился бы к нему только как к средству» [Кант, Т. 4, ч.1, 1965: 270].

2 Об этом подробнее будет сказано чуть позже.
} 
Глобализм постмодернистских текстов, экспансия искусства в новые сферы, поиски индивидуальных духовных путей личного совершенствования, в том числе религиозных, к примеру, в рамках Нью Эйджа ${ }^{3}$, ставят перед человеком задачу предельно возможного вмещения кардинально иных индивидуальных картин мышления. Эти онтологические характеристики современности снова возвращают нас к необходимости изучения феномена сознания. Сложности при постижении работы индивидуального сознания и его функционирования в рамках творческих процессов добавляет и ряд открытий генетиков. Одно из них говорит о том, что есть гены, включающиеся только при освоении новационной для конкретного индивида информации, не участвующие в большинстве реализуемых ежедневно процессов, которые протекают во многом автоматически на бессознательном уровне.

Психолог Виктор Аллахвердов утверждает, что в том числе и с помощью энцефалограммы можно показать, что не просто большая часть «практически всё, что мы обычно считаем достоянием сознания, делается вначале неосознанно» и только некоторая часть затем «освещается лучом сознания» [Аллахвердов, 2017]. Учёный говорит об исследованиях и статистических наблюдениях, позволяющих сделать вывод о том, что мозг ошибается в одних и тех же местах, то есть в своём роде «он запоминает ошибку». Такое утверждение может быть также прямо связано с эмоциональным восприятием человеком мира, мы можем ошибаться в деталях и повторно не вникать в особенности подобным образом по отношению к вещам, которые нам не так интересны. Здесь уместна корреляция с открытием учёных, согласно которому у человека есть гены, чья активность фиксируется только когда запоминаются важные вещи и надолго.
По словам нейробиолога К. Анохина, изначально за основу была взята гипотеза конца XIX века о том, что процессы запоминания в нервных клетках похожи на процессы роста, когда развивается нервная система, и используют те же механизмы. Позднее были обнаружены гены (семейства генов, к примеру, ген c-fos), которые работают во время развития, а затем отвечают за регуляцию процессов развития мозга как следствие нашего индивидуального опыта. Эти гены во взрослом состоянии включаются в ситуации субъективной новизны, то есть активируются (экспрессируют) в связи с обучением. «Каждый эпизод новизны и нашего опыта - это обращение к геному и маленький всплеск морфогенеза в нашем мозге» [Анохин, 2017]. То, что было новым в опыте и то, что запомнилось, изменило связи, и мозг вырос в определённых направлениях и связях он дифференцировался в этих связях - это продолжающееся развитие. Одни связи при этом разрастаются, а другие подавляются, нейроны специализируются - это необратимый процесс. В гипокампе нейроны появляются и во взрослом мозге, рождаясь заново и у животных, и у человека [Анохин, 2017].

В то же время, согласно современным исследованиям, человек с нарушением эмоционального фона не может длительное время принять достаточно простого повседневного решения. Таким образом, с различных своих сторон проблема как познания, так и самореализации посредством творчества прямо связана с эмоциональными проявлениями, имеющими индивидуально-социальный характер. Французский врач Жан Марк Гаспар Итар, который известен, в том числе своими занятиями с найденным около 1800-го года мальчиком-дикарём, названным позже Виктором, отмечал у него отсутствие спектра человеческих эмоций, в особенности чувства юмора.

\footnotetext{
3 Религии Нового века, предложившие индивидуальную свободу поиска и отход от единства некой конкретной традиции.
} 
Итар писал: «... Его ухо не было органом для восприятия звуков, их артикуляции и их сочетаний, оно было ничем иным, как простым средством самосохранения, которое предупреждало о приближении опасного животного или о падении диких фруктов» [Itard, 1962: 26]. Позднее, указывая на прогресс Виктора в сфере эмпатии, отличающей, по мнению Итара, человека, в своём сообщении он указывал на демонстрацию Виктором утешительного поведения, когда тот прекратил делать то, чем он занимался, видя слёзы экономки, мадам Герен (фp. Guerin) по поводу утраты ею мужа [Malson, 1964: 234].

Николай Козлов в рамках своей теории социального психоанализа эмоций выдвигает гипотезу о том, что спектр врождённых эмоций человека исторически расширяется и, более того, имеет генетическую корреляцию с национальной ментальностью и даже с эмоциональной атмосферой конкретной семьи на уровне нескольких поколений [Козлов, 2013]. В процессе развития ребёнок учится и также присваивает целый ряд социальнораспространённых эмоций.

В публичной лекции 2017 г. для Далай-Ламы нейрофизиолог Юрий Александров утверждал: «Нет концепции эмоции как независимой категории. Эмоции - это зависимая категория и не может рассматриваться независимо от познания» [Александров, 2017]. Согласно его теории, основанной на результатах исследований, новые знания коррелируют с усвоенными и стимулируются индивидуальной потребностью уже специализированных нейронов. Из этого можно сделать вывод о том, что увлечённость определённой сферой деятельности может порождать эмоциональную потребность дальнейшего познания в заданном направлении.

По метафорически парадоксальному утверждению Татьяны Черниговской, «единственное, что мозг не может делать, он не может не учиться» [Черниговская, 2017]. Тем не менее, когда потенциал возможного нового в данной сфере исчерпан, процесс познания не- редко смещается в другое направление или на новый уровень, объединяющий ряд областей. Видимо, именно поэтому, как метко замечает биофизик Всеволод Твердислов, «с возрастом люди начинают думать более общими вещами» [Твердислов, 2015]. В целом, как характер, так и сам спектр эмоциональных проявлений имеют очевидную корреляцию с деятельностью в социуме и направлением жизненной активности конкретного индивида, являясь своеобразным «путеводителем по Вселенной». Следует отметить также ряд исследований, напрямую связанных с построением индивидуальной картины мира, а, следовательно, и с проблемой целеполагания.

Проблема субъективного понимания благополучия лежит в области интересов нобелевского лауреата Даниэля Канемана. Его работы (совместно с психологом Амосом Тверски) связаны с изучением рационального мышления и механизмов принятия решения, в результате чего открыт ряд когнитивных иллюзий человека. С помощью исследований была показана квази-рациональная природа мышления человека и роль эмоционального контекста, который существенно влияет на стратегии рискового поведения и выбора принимаемых человеком решений. Подобная постановка проблемы также привела его к изучению роли эмоций. В последнее время Канеман проводил исследования в области того, как люди реконструируют свой жизненный опыт и что они о нём думают, включая вопросы эмоционального предвидения.

По его мнению, запомненная полезность и испытываемая полезность - не одно и то же, для памяти имеют значение пик и окончание испытанного, а не время - длительность. Переживающее «Я» живёт в психологическом настоящем, помнящее «Я» оценивает то, как всё было и только оно обладает длительностью и принимает решения о будущем. Непонятно, что имеет для здоровья людей большее значение: то, что они думают о своей жизни или количество эмоционального стресса. Для ощущения счастья также важно внимание. Человек 
не получает удовольствие от происходящего в данный момент, если доминанта внимания смещена на что-то другое, значение чего он иногда преувеличивает. Внимание - главный механизм адаптации к новым обстоятельствам [Канеман, 2002].

Творческие процессы и переживаемое состояние счастья стали предметом изучения и такого исследователя, как Михай Чиксентмихайи, в рамках своей «теории потока» который рассматривает творчество как некое состояние прострации, включающееся в мозгу [Csikszentmihalyi, 2008].

Непосредственный научный интерес вызывают процессы внутри мозга человека при реализации творческих задач, включая музыку. Британский нейробиолог Семир Зеки (Semir Zeki), которому принадлежит термин нейроэстетика, исследует нейрооснования креативности, и то, как мозг получает удовольствие от созерцания искусства. В числе последних работ изучение им проблемы нейронных коррелятов в аффективных состояниях, таких, как восприятие любви, страсти (желания) и красоты, которые порождаются данными органов чувств. Практические исследования о влиянии аудио информации на мозг, связанные с существенными отличиями в процессах обработки вербальной и музыкальной тональной информации, ведёт Роберт Зэторра, результаты представлены в работе о музыке и речи [Zatorre, Baum, 2012]. Тем не менее, изучение научными методами таких процессов как создание и переживание индивидуальной вселенной или обмен индивидуальноуникальными проявлениями человеческой природы мышления имеет явные ограничения.

Язык науки сформировался во многом в полемике с религиозной парадигмой мышления. Следуя за максимой У. Оккама $^{4}$ о том, что не надо множить сущности без необходимости, он имеет в числе задач отрицание недоказуемого, что само по себе ограничивает спектр легитимных явлений, а, следовательно, задаёт тем самым некие координаты и границы мышления, значимости познаваемых явлений. В число последних попадают преимущественно явления, отвечающие массовой верификации, в то время как индивид постоянно множит символическую реальность своим воображением и персональной жизненной историей своих впечатлений.

Подобная ситуация, а также пересмотр ряда мировоззренческих и философских оснований, спровоцированный социальными переменами, может стимулировать поиски решения данного парадокса в различных направлениях. Представляется, что одно из них - это поиск языка, возможно, отличающего следующую гносеологическую фармацию, предназначенного для передачи максимума индивидуализированной информации, но имеющего коммуникативноинтерактивный характер. Учитывая колоссальные различия в индивидуальных способностях конкретных людей, актуальным становится поиск языка для максимального и в тоже время интерактивного доступа к миру конкретной личности. Возможно, это не только язык коммуникации, но и язык познания окружающего мира в целом, который сможет в перспективе иметь не меньшее значение, чем научный способ познания.

Изучение семантического потенциала музыки в данном контексте обладает особой значимостью, поскольку коммуникативные возможности музыки имеют прямое отношение и к эмоциональной выразительности и к процессу познания. Важным свойством музыкального языка является полисемантичность, заданная изначальной множественностью организационных структур (выразительность тембра, динамики, ритма и т. д.) и существующая до появления кодов (жанровых, стилевых и т. п.) конкретного произведения. При этом ни одна из структур, включая доминирующую звуковысот-

4 «...Множественность никогда не следует полагать без необходимости...» [Смирнов, 2010]. 
ность, как и язык в целом, не обладает уровнем условного знака, поскольку ни один отдельно взятый выразительный фрагмент «не имеет денотата» [Арановский, 1974: 104].

В этой связи каждый элемент априори находится в структурной точке пересечения различных закономерностей, вызывая при восприятии необходимость применения множества дешифрующих кодов. Следствием являются: высокая смысловая нагруженность, придающая элементу индивидуальный внесистемный характер, что затрудняет действие дискурсивной стратегии интеллекта; а также «применение многократных и разных кодов», связанное с повышенным уровнем чувственного наслаждения [Лотман, 1970:77], что обеспечивает музыкальному языку (наряду с феноменом звуковых проявлений) доминанту эмоционального воздействия. То есть законы реконструкции образа здесь выводимы «путём введения алогического момента из категорий самого смысла» [Лосев, 1990: 297].

Его художественное содержание обращено преимущественно к конкретночувственной сфере мышления, охватывающей мир в целостных образах, позиционируя звуковые представления как «смыслозвуковое обобщение» [Meдушевский, 1993: 151]. Их ясность зависит от того, насколько различные семантические параметры (от характерной интонации до целостности музыкального фрагмента) подчинены авторской идее и доступны для смысловой идентификации слушателем. Под влиянием эмоционального воздействия в процессе восприятия стимулируются также продуктивные процессы психики, способствующие осмыслению неосознанных сразу, а потому диссимилированных сознанием свойств образа. В свою очередь сверхфразовое единство музыкального фрагмента возникает из иерархичности интонационной организации, сочетающей как минимум два вида взаимовлияний: прямой (некая смысловая связь в сознании реципиента соседних интонаций) и опосредованный (осмысление апостериори интонаций, не идентифицированных в момент звучания).

В итоге, посредством музыки наиболее полно выражаемы эмоции высшего уровня - чувства, которые передают общее для переживания многих людей. В то же время интеллект, репродуцируя былые переживания, способен «формировать такие эмоции, которых никогда ещё не ведал человек» [Раппопорт, 1978: 76]. То есть комбинация произвольно взятых звуков музыкальной темы, выражая предельно обобщённое эмоциональноидейное отношение к миру, способна при этом отобразить процесс наиболее тонко и индивидуально, вызывая спектр эмоций, выходящих за рамки осознанных и зафиксированных в слове.

В целом, музыка - это язык, в котором нет предсказуемого варианта соотнесения множества кодов, он не может привести человека к определённому выводу или результату, а потому априори провоцирует познание. Таким образом, музыкальная выразительность в будущем может не ограничиваться предпочтительно сферой искусства, но и имеет потенциал использоваться в качестве составляющей развёрнутого интерактивного общения. Здесь уместно упомянуть сино-тибетское семейство языков, где звуковысотная направленность интонации уже корректирует семантическое значение слова.

Таким образом, если передовые умы планеты заговорили о том, что им тесно в рамках научного способа познания и научной картины мира в принципе, то это только вопрос времени, когда начнут появляться новые языки, способные реализовать качественно иные возможности в сфере познания. В свою очередь, интерактивный язык, максимально передающий индивидуальный мир, и реализующий новый способ ведущей системы познания может быть основан, в том числе и на музыкальной семантике. 


\section{Список литературы:}

Аверкин А.Н., Гаазе-Рапопорт М.Г., Поспелов Д.А. Толковый словарь по искусственному интеллекту. 1992. [Электронный ресурc]. - URL: http://www.raai.org/library/tolk/aivoc.html\#L208 (дата обращения 26.04.2018).

Александров Ю.И. Мозг - психика - культура с позиций системно-эволюционного подхода. 2018. [Электронный ресурc]. - URL: https://www.youtube.com/watch?v=UZz2m1lfUk4\&t=5s (дата обращения: 19.03.2018).

Александров Ю.И. Недизъюнктивный подход к пониманию сознания и эмоций: культурноспецифический взгляд. / Далай-лама и российские ученые. Диалоги о природе сознания. Сессия 2. 2017. [Электронный ресурc]. - URL: https://www.youtube.com/watch?v=_ba9wivnpPk\&t=80s (дата обращения: 13.10.2018).

Аллахвердов В.М. Человек разумный? Ночь. Интеллект. №1. Т.В. Черниговская с Виктором Аллахвердовым. 2017. [Электронный ресурc]. - URL: https://www.youtube.com/ watch?v=EsOh5AxTBRA\&t=104s (дата обращения: 14.04.2018).

Анохин К.В. «Вспомнить всё». 2017. [Электронный ресурс]. - URL: https://www.youtube.com/ watch?v=Zeg5UkO_0k0\&t=3544s (дата обращения: 14.06.2018).

Арановский М.Г. Мышление, язык, семантика // Проблемы музыкального мышления: сб. ст. под ред. М. Арановского. М.: Музыка, 1974. С. 90-129.

Канеман Д. Исследование разума: интуиция - чудеса и ошибки. 2002 (публ. 2016). [Электронный pecypc]. - URL: https://www.youtube.com/watch?v=ppK8dPnkU8g (дата обращения: 26.11.2018).

Кант И. Сочинения в шести томах. Т. 4, ч.1. М: Мысль, 1965. 544 с.

Козлов Н.И. Теория социального психоанализа эмоций. 2013. [Электронный ресурс]. - URL: https://www.youtube.com/watch?v=A3SLE_1lkKA\&t=40s (дата обращения: 19.08.2018).

Лосев А.Ф. Музыка как предмет логики // Из ранних произведений. М.: Изд-во «Правда», 1990. C. 195-394.

Лотман Ю.М. Структура художественного текста. М.: Искусство, 1970. 384 с.

Медушевский В.В. Интонационная форма музыки. М.: Композитор, 1993. 262 с.

Раппопорт С.Х. От художника к зрителю. М.: Сов. художник, 1978. 237 с.

Смирнов Г.А. Оккам, Уильям // Новая философская энциклопедия / Ин-т философии РАН. - 2-е изд., испр. и допол. Т. 1-4. М.: Мысль, 2010. 2816 с.

Твердислов В.А. Великое в малом. Человеческая память: известное о неизвестном. 2015. [Электронный ресурc]. - URL: https://www.youtube.com/watch?v=S5kc3SFg9_4 (дата обращения: 27.08.2018).

Черниговская Т.В. «ЗАЧЕМ НУЖНО ЧИТАТЬ КНИГИ???». 2017. [Электронный ресурс]. - URL: https://www.youtube.com/watch?v=RpPJr3dj5bQ\&t=140s. (дата обращения: 10.05.2018).

Csikszentmihalyi M. Flow: The Psychology of Optimal Experience. Publisher: Harper Perennial Modern Classics; 1 edition (July 1, 2008). 334 p.

Itard J.-M.-G. The Wiid Boy of Aveyron. New York: Meredith Company, 1962. 104 p.

Malson, L. Les enfants sauvages. Mythe et réalité. Paris: Union générale des éditeurs, Collection 10/18. 1964. 398 p.

Penrose R. The Emperor's New Mind: Concerning Computers, Minds and the Laws of Physics. Oxford University Press, 1989. $480 \mathrm{p}$.

Zatorre R.J., Baum S.R. Musical Melody and Speech Intonation: Singing a Different Tune, PLOS Biology, 2012, DOI: 10.1371/journal.pbio.1001372. [Электронный ресурc]. - URL: https://journals.plos.org/ plosbiology/article?id=10.1371/journal.pbio.1001372\#s2 (дата обращения: 27.06.2018).

\section{6 aвmope:}

Алексеева Мария Викторовна - к.филос.н., выпускница Российской академии музыки им. Гнесиных, доцент кафедры связей с общественностью Московского государственного технического университета гражданской авиации (МГТУ ГА). Россия, 125993, Москва, Кронштадт- 
ский бульвар, 20. Область научных интересов - философия, культурология, медиакультура, музыкальная эстетика, в частности выразительные возможности взаимосвязи вербальной и музыкальной семантики. E-mail: alekxm@mail.ru.

\title{
COMMUNICATIVE POTENTIAL OF MUSICAL EXPRESSIVENESS
}

\section{M.V. Alekseeva}

Moscow State Technical University of Civil Aviation (MSTUCA). 20 Kronshtadtskiy bul'var, Moscow, 125993, Russia.

\begin{abstract}
This article offers a brief overview of some challenges and paradoxes of contemporary research as well as various social questions related to them. Key problems of consciousness research are stated relating to the scientific work on artificial intelligence development. Due to such ambitious objectives of modern science, there is a special attention to personality sphere, to its emotional sufferings and personal creative aspirations. The proposed theses of research of the communicative and creative possibilities of the musical language, its qualitative differences from the considered potential of verbal semantics give a clear idea that the language of music is directly related to emotional expressiveness and cognitive process stimulation. As a result of such a summary, it becomes obvious that the study of verbal and musical expressive possibilities, their comparative analysis in the realities of cultural and communication tendencies of modernity is not limited to the needs of the sphere of art. The article also addresses communicative possibilities of musical expressiveness in light of the ability of music to convey the flow of personal emotions.

The novelty of this article is to substantiate further detailed study of musical expression communication possibilities, which will make personal emotional world accessible, i.e. qualia. In turn, the status of qualia is considered as one of the most acute and widely discussed problems in modern philosophy, since representatives of various fields of science often see it as a key to understanding the nature of consciousness.
\end{abstract}

Key words: cognitive Sciences, consciousness, emotions, intuition, musical semantics, creativity, morality, artificial intelligence

\section{References:}

Averkin A.N., Gaaze-Rapoport M.G., Pospelov D.A. Tolkovyy slovar' po iskusstvennomu intellektu [Explanatory Dictionary of Artificial Intelligence]. 1992. Available at: http://www.raai.org/library/tolk/aivoc. html\#L208 (accessed 26 April 2018) (In Russian).

Aleksandrov YU.I. Mozg - psikhika - kul'tura s pozitsiy sistemno-evolyutsionnogo podkhoda [Brain - psyche - culture from the standpoint of a system-evolutionary approach]. 2018. Available at: https:// www.youtube.com/watch?v=UZz2m1lfUk4\&t=5s (accessed 19 March 2018) (In Russian).

Aleksandrov YU.I. Nediz"yunktivnyy podkhod k ponimaniyu soznaniya i emotsiy: kul'turno-spetsificheskiy vzglyad. / Dalay-lama i rossiyskiye uchenyye. Dialogi o prirode soznaniya. Sessiya 2 [A nondisjunctive approach to understanding consciousness and emotions: a culturally specific view. The Dalai Lama and Russian scientists. Dialogues about the nature of consciousness. Session 2]. 2017. Available at: https://www.youtube.com/watch?v=_ba9wivnpPk\&t=80s (accessed 13 October 2018) (In Russian).

Allakhverdov V.M. Chelovek razumnyy? Noch'. Intellekt. №1. T.V. Chernigovskaya s Viktorom Allakhverdovym [Homo sapiens? Night. Intelligence. No. 1. T.V. Chernigovskaya with Victor Allahverdov]. 2017. Available at: https://www.youtube.com/watch?v=EsOh5AxTBRA\&t=104s (accessed 14 April 2018) (In Russian). 


\section{ИСКУССТВО}

Anokhin K.V. «Vspomnit' vso» ["Remember everything"]. 2017. Available at: https://www.youtube. com/watch?v=Zeg5UkO_0k0\&t=3544s (accessed 14 June 2018) (In Russian).

Aranovskiy M.G. Myshleniye, yazyk, semantika // Problemy muzykal'nogo myshleniya: sb. st. pod red. M. Aranovskogo [Thinking, language, semantics // Problems of musical thinking: a collection of articles edited by M. Aranovsky]. Moscow, Publishing House "Music", 1974. pp. 90-129 (In Russian).

Kahneman D. Issledovaniye razuma: intuitsiya - chudesa i oshibki [Mind Study: Intuition - Miracles and Mistakes]. 2002 (publication 2016). Available at: https://www.youtube.com/watch?v=ppK8dPnkU8g (accessed 26 November 2018) (In Russian).

Kant I. Sochineniya v shesti tomakh [Works in six volumes]. Volume 4, part 1. Moscow, Publishing House "Thought", 1965. 544 p. (In Russian).

Kozlov N.I. Teoriya sotsial'nogo psikhoanaliza emotsiy [The theory of social psychoanalysis of emotions]. 2013. Available at: https://www.youtube.com/watch?v=A3SLE_1lkKA\&t=40s (accessed 19 August 2018) (In Russian).

Losev A.F. Muzyka kak predmet logiki // Iz rannikh proizvedeniy [Music as a subject of logic // From early works]. Moscow, Pravda Publishing House, 1990. pp. 195-394 (In Russian).

Lotman YU.M. Struktura khudozhestvennogo teksta [The Structure of the artistic text]. Moscow, Publishing House "Art", 1970. 384 p. (In Russian).

Medushevskiy V.V. Intonatsionnaya forma muzyki [Intonational form of music]. Moscow, Publisher "Composer", 1993. 262 p. (In Russian).

Rappoport S.KH. Ot khudozhnika k zritelyu [From artist to viewer]. Moscow, Publishing house "Soviet artist", 1978. 237 p. (In Russian). Smirnov G.A. Okkam, Uil'yam // Novaya filosofskaya entsiklopediya [Ockham, William // New Philosophical Encyclopedia] / Institute of Philosophy of the Russian Academy of Sciences. - Second edition, volumes 1-4. Moscow, Publishing House "Thought", 2010. 2816 p. (In Russian).

Tverdislov V.A. Velikoye v malom. Chelovecheskaya pamyat': izvestnoye o neizvestnom [Great in the small. Human memory: the known of the unknown]. 2015. Available at: https://www.youtube.com/ watch?v=S5kc3SFg9_4 (accessed 27 August 2018) (In Russian).

Chernigovskaya T.V. «Zachem nuzhno chitat' knigi???» ["Why do you Need to Read Books???"]. 2017. Available at: https://www.youtube.com/watch?v=RpPJr3dj5bQ\&t=140s. (accessed 10 May 2018) (In Russian).

Csikszentmihalyi M. Flow: The Psychology of Optimal Experience. Publisher: Harper Perennial Modern Classics; 1 edition (July 1, 2008). 334 p.

Itard J.-M.-G. The Wiid Boy of Aveyron. New York: Meredith Company, 1962. 104 p.

Malson, L. Les enfants sauvages. Mythe et réalité. Paris: Union générale des éditeurs, Collection 10/18. 1964. 398 p. (in French).

Penrose R. The Emperor's New Mind: Concerning Computers, Minds and the Laws of Physics. Oxford University Press, 1989. 480 p.

Zatorre R.J., Baum S.R. Musical Melody and Speech Intonation: Singing a Different Tune, PLOS Biology, 2012, DOI: 10.1371/journal.pbio.1001372. Available at: https://journals.plos.org/plosbiology/ article?id=10.1371/journal.pbio.1001372\#s2 (accessed 27 June 2018).

\section{About the Author:}

Maria V. Alekseeva - PhD in Philosophy, graduate of the Russian Academy of Music named after Gnesins, Associate Professor of the Public Relations Chair, Moscow State Technical University of Civil Aviation (MSTUCA). 20 Kronshtadtskiy bul'var, Moscow, 125993, Russia. Research interests are philosophy, cultural studies, media culture, musical aesthetics, in particular the expressive possibilities of the relationship between verbal and musical semantics. E-mail: alekxm@mail.ru. 